\title{
Currículos de formação de professores de língua portuguesa: instituições autônomas e o poder de sua história
}

Sonia T. S. Penin

Cláudia V. A. Galian

Vera Valdemarin

Resumo

Baseia-se em uma pesquisa interinstitucional que focaliza o âmbito mais amplo em que são formuladas e implementadas as políticas de formação de professores no Estado de São Paulo. Tem por objetivo contribuir para a elucidação das forças presentes em movimentos de reforma curricular nos cursos de licenciatura, cotejando dados e aspectos socioculturais e institucionais circundantes. A análise incide sobre projetos pedagógicos de dois cursos de Letras de duas universidades públicas paulistas. Essas instituições desenvolveram, nos últimos anos, projetos ou ações de formação de professores para a escola básica, e é nesse contexto que se inserem os projetos pedagógicos analisados, que são tomados como exemplos de caminhos diferenciados que as universidades traçam, influenciadas pela história de cada instituição. O procedimento de pesquisa adotado foi a análise documental e o conceito de currículo em processo orientou as reflexões desenvolvidas. Reafirma-se, como em outros estudos, que a necessária integração entre saberes pedagógicos e saberes provenientes da área de referência continua sendo tarefa difícil, que as circunstâncias na criação dos cursos e a formação superposta deixou suas marcas nas instituições e que as tentativas para superá-la constituem exemplos esparsos e não modelos generalizados, o que ressalta 
a relevância da continuidade das pesquisas sobre o currículo dos cursos de licenciatura.

Palavras-chave: formação de professores; currículo; educação superior.

\section{Abstract \\ Portuguese teachers education curricula: autonomous institutions and the power of their histories}

The article is based on an inter-institutional research that focuses on the broader context in which policies for teacher education are formulated and implemented in the São Paulo state. Also, it aims to contribute to the elucidation of the present forces in movements of curricular reform in undergraduate courses, collating data and socio-cultural and institutional surrounding aspects. The analysis focuses on the educational projects of two Language courses of two public universities in São Paulo. These institutions have, in recent years, developed projects or actions of teacher training for basic school, and, it is in this context that the pedagogical projects are analyzed, that is, they are taken as examples of differentiated paths that universities create, influenced by their history. The research procedure adopted was based on document analysis; besides, the concept of curriculum in process also oriented the developed reflections. As in other studies, the paper reasserts that the necessary integration between pedagogical knowledge and knowledge from areas of reference remains difficult. Also, that the existing circumstances in the creation of courses and the superimposed training left their marks on the institutions, and attempts to overcome them are sparse and do not represent generalized models. That emphasizes the importance of the continuation of research about the curriculum of undergraduate courses.

Keywords: teacher training; curriculum; higher education.

\section{Introdução}

Este texto discute o que se expressa como projeto formativo para professores de Língua Portuguesa que atuarão no ensino básico, em duas universidades, instituições autônomas de ensino superior, focalizando aspectos do seu processo de escolhas ante as definições legais de nível nacional e a sua própria história.

O campo da formação docente no País tem sido profundamente impactado pelas reformas educacionais em curso, deflagradas nos anos 1990, as quais vêm sendo amplamente analisadas em suas implicações 
sociais, políticas e pedagógicas (Kuenzer, 1999; Pereira, 1999; Freitas, 2003; Marques e Pereira, 2002; Carvalho, 2001; Ludke et al., 1999; Maués, 2003; Rego e Mello, 2004). O crescimento dos cursos de formação de professores, em resposta ao aumento das oportunidades de acesso da população à educação básica, assim como a persistência de indícios da baixa qualidade da aprendizagem dos alunos em todos os níveis de ensino, tem desafiado todo o sistema educacional brasileiro, desde legisladores e propositores até pesquisadores de políticas públicas para a educação, dentro de amplo espectro e em diferentes instâncias federativas e instituições envolvidas com o ensino básico, tocando em questões que passam pelos currículos de formação profissional e por caminhos abertos à profissionalização e à profissionalidade docente ao longo da carreira.

Os embates atuais acerca dos modelos de formação docente e a insatisfação que provocam não ocorrem somente no Brasil, estando também presentes nos países ocidentais de modo geral, tanto na América Latina quanto nos de capitalismo avançado do hemisfério norte. Lá e aqui, respeitando certos limites, os processos de elevação dos patamares de formação do magistério não têm dado conta dos reclamos sobre a qualidade do ensino básico e das demandas mutáveis das sociedades contemporâneas, agravadas aqui e na América Latina pelas velhas questões sociais não resolvidas.

No tocante às licenciaturas que formam professores para os anos finais do ensino fundamental e para o ensino médio, as mudanças que se seguiram à Lei de Diretrizes e Bases da Educação Nacional de 1996 (LDB $n^{\circ}$ 9.394) alteraram profundamente a relação entre os conhecimentos referentes aos fundamentos da educação e ao sistema educacional, as disciplinas instrumentais e os saberes de referência das diferentes áreas do conhecimento. Embora o eixo da formação do chamado professor especialista situe-se junto às áreas específicas, cobra-se uma articulação diferente entre o específico e o pedagógico, para além de uma relação apenas temporal de sucessão que a tradicional organização curricular consagrou, conhecida como o esquema " $3+1$ " - três anos de formação específica seguidos de um ano de formação pedagógica - que sobrevive em vários projetos de formação. Se a competência básica do professor pode ser considerada como o domínio do conteúdo específico - como admitem Ludke (1994), Ludke e Cruz (2005), Oliveira (2006), Ponte (2000) e outros tantos -, um desafio permanece, a despeito de todas as indicações da literatura sobre formação: romper com a dicotomia entre o conteúdo específico e a sua dimensão pedagógica.

Nesse sentido, é de capital importância o estudo da licenciatura no currículo de Letras, uma vez que o estudo da língua materna perpassa todas as séries do ensino básico.

A importância do domínio do saber de referência da área na qual o professor atua ou deverá atuar é colocada como condição para a construção da profissão docente também por pesquisadores do ensino de língua materna como Oliveira, que compartilha com Shulman (1986) "o entendimento de que é necessário que o professor domine os conteúdos 
específicos de sua área, além de ter a clareza de como esses conteúdos transformam-se em objeto de ensino" (Oliveira, 2006, p. 2). No entanto, na análise das grades curriculares dos cursos de licenciatura em Letras de várias universidades federais do País, a autora aponta que mais de 80\% dos conteúdos das disciplinas são voltados para estudos descritivos da língua, aliados a concepções de gramáticas prescritivas e a uma visão normativa da língua. O estudo de Silva (2005), que analisa representações de professoras do ciclo I de uma escola pública no interior do Estado de São Paulo, constata que entre as prescrições dos currículos de formação inicial e as práticas efetivas permanece um lapso preenchido pelas representações das professoras, marcadas por influências de diversas ordens, uma vez que as práticas desenvolvidas e os procedimentos adotados não estariam contidos na mesma forma lógica que caracterizava antes a valorização do sistema das formas gramaticais (Silva, 2005, p. 111).

\section{Contexto da pesquisa}

Dialogando com o quadro motivador acima descrito, desenvolve-se uma pesquisa interinstitucional ${ }^{1}$ que focaliza as representações de professores de cursos de licenciatura, considerando o contexto específico de cada um deles e de cada uma das universidades em questão, assim como o âmbito mais amplo em que são formuladas e implementadas as políticas de formação de professores.

Entre os resultados desse projeto, que tem por objetivo contribuir para a elucidação das forças presentes em movimentos de reforma curricular nos cursos de licenciatura, cotejando dados e aspectos socioculturais e institucionais circundantes, delimitamos no presente texto a análise dos projetos pedagógicos de dois cursos de Letras de duas universidades públicas paulistas.

As universidades - aqui denominadas A e B - desenvolveram, nos últimos anos, projetos ou ações de formação de professores para a escola básica, e é nesse contexto que se inserem os projetos pedagógicos analisados. Esses documentos são tomados como exemplos de caminhos diferenciados que as universidades traçam, influenciadas pela história de cada instituição. As diferentes trajetórias podem ser interpretadas como adaptação ou resistência, conforme destacam Scheibe e Bazzo (2013):

A reforma educacional brasileira, que teve como marco de referência central a promulgação da Lei de Diretrizes e Bases (LDB) nº 9.394/1996 [...], continua em curso e o que se percebe é que as instituições de ensino superior adaptam-se lentamente à nova legislação, ou a ela resistem, em especial no que diz respeito às novas diretrizes curriculares instituídas para a totalidade dos cursos existentes (p. 18).

Todavia, há que se aprofundar em cada instituição o sentido do caminho trilhado, buscando apreender especificidades da gênese e da genealogia de práticas e documentos atualmente vigentes. Os procedimentos adotados na pesquisa foram a análise documental, que

\footnotetext{
${ }^{1}$ Trata-se da pesquisa "Política e currículos de formação para a docência na Educação Básica: saberes e representações de professores universitários", desenvolvida pelo Grupo de Pesquisa Cursare (Currículo, Saberes e Representações na Formação de Professores), no NAP-USP (Núcleo de Pesquisa da Universidade de São Paulo) e articulada ao CIERS-ed (Centro Internacional de Estudos em Representações Sociais, Subjetividade Educação) e à Cátedra Unesco sobre profissionalização docente, sediada no DPP (Departamento de Pesquisas Educacionais) da Fundação Carlos Chagas, São Paulo.
} 
incidiu sobre os projetos pedagógicos dos cursos de licenciatura em Letras - aspecto destacado neste texto - e as entrevistas semiestruturadas com dez professores das duas universidades. Como procedimentos de análise dos dados levantados nos documentos utilizou-se a análise de conteúdo e as informações destacadas dos documentos foram organizadas nas seguintes categorias: (1) objetivos, (2) perfil do egresso, (3) organização do curso, (4) papel da pesquisa e do estágio na formação de professores.

\section{O currículo prescrito}

Na análise dos documentos, assume-se que eles, além de estabelecer parâmetros para a prática, permitem compreender valores e objetivos assumidos para a formação de professores. Confere-se importância, portanto, à dimensão prescrita do currículo, entendida como a expressão de um equilíbrio instável em torno de diferentes concepções e interesses envolvidos na definição do que deve compor o lote de conhecimentos a serem desenvolvidos na formação de professores. Não se trata de ignorar a potência das demais dimensões do currículo, tomado aqui em sua perspectiva processual (Gimeno Sacristán e Pérez Gómez, 1998), mas de ressaltar que os documentos curriculares têm significados que são reconhecidos diferenciadamente pelos agentes que participam de sua implementação e desenvolvimento e que ambas as dimensões - a prescrita e a real - são elementos igualmente importantes para a constituição do plano formativo assumido. Assim como Goodson (1997), assume-se, portanto, que o currículo prescrito não é uma dimensão a ser desprezada, uma vez que estabelece determinados referenciais para a formação de professores e, como aspecto não menos importante, atrai ou afasta recursos para os diferentes cursos e disciplinas:

O currículo escrito é o testemunho visível das racionalidades escolhidas e da retórica legitimadora das práticas [...] constituindo o aspecto tangível de uma padronização de recursos (financeiros, avaliativos, materiais, etc.). [O currículo escrito] proporciona-nos um testemunho, uma fonte documental, um mapa variável do terreno: é também um dos melhores roteiros oficiais para a estrutura institucionalizada da educação (p. 20)

O primeiro ponto a ser destacado para evidenciar o tipo de aproximação escolhida para o desenvolvimento da análise é a concepção processual de currículo, segundo a qual o currículo é visto como o resultado de práticas desenvolvidas em diferentes dimensões, não sendo possível compreendê-lo por meio da análise de qualquer uma delas isoladamente. Tais dimensões são, segundo Gimeno Sacristán (1998): (1) o currículo prescrito e regulamentado, aquele que se constrói no âmbito de decisões políticas e administrativas; (2) o currículo planejado para professores e estudantes, expresso no desenvolvimento de materiais, guias etc.; (3) o currículo organizado nas diferentes instituições de ensino, ou seja, as práticas organizacionais em torno do currículo; (4) o currículo em 
ação, a reelaboração das prescrições na prática docente, nos planos dos professores, nas suas ações e nas tarefas acadêmicas desenvolvidas junto aos alunos; e (5) o currículo avaliado, materializado nas práticas de controle internas e externas (p. 139).

Nessa forma de teorização sobre o currículo, compreender o caminho de transformação das prescrições legais implica atentar para o fato de que:

para conhecer o currículo é preciso ir muito além das declarações, da retórica, dos documentos, ou seja, ficar muito mais próximo da realidade. [...] pelas propostas do currículo, expressam-se mais os desejos do que as realidades. Sem entender as interações entre ambos os aspectos não poderemos compreender o que acontece realmente aos alunos/as e o que aprendem (Gimeno Sacristán, 1998, p. 137).

Outro aspecto valorizado na análise proposta é a ideia de que o currículo é terreno de contestação, fragmentação e mudança (Goodson, 1997), ou seja, não se ignora aqui a instabilidade do que está expresso no documento curricular e tampouco a existência de vozes historicamente caladas no processo de produção desses referenciais. Portanto, admite-se que o currículo não é neutro e que está constantemente sob pressão.

Nesse sentido, no que se refere ao processo de adaptação das instituições de ensino superior às definições legais assumidas a partir da LDB de 1996, especialmente focalizado neste artigo, Scheibe e Bazzo (2013) indicam:

Esse processo, vagaroso e difícil pelo que encerra de interesses em jogo, não ocorreu nem ocorre ainda sem dissensos e conflitos, pois trata também de romper com uma tradição iniciada no país em 1934, quando da criação dos primeiros cursos de formação de professores. Afinal, o conhecido modelo " $3+1$ " [...] então instaurado vigorou ao longo de mais de sessenta anos, com a aceitação explícita da maioria dos docentes universitários que atuavam nos cursos de formação de professores, porém vinculados às disciplinas pertencentes ao campo de conhecimento da área específica. Em paralelo, os docentes envolvidos diretamente com a formação pedagógica dos futuros professores, [...], conviveram ao longo de mais de trinta anos com uma permanente discussão em torno da necessidade de substituir tal modelo. Esta ousadia criou muitos dissensos e conflitos que refletem ou se vinculam não apenas a aspectos administrativo-organizacionais das instituições, mas - e principalmente - às relações de poder há longo tempo nelas instauradas (p. 23).

Assim, ainda que o recorte realizado na pesquisa tenha incidido apenas sobre a dimensão prescrita do currículo, elucida-se a impossibilidade de se conhecer um currículo apenas pela entrada nos documentos curriculares e, especialmente, sem situá-lo no processo histórico que envolve as determinações legais e as estratégias desenvolvidas para lidar com elas em cada instituição.

Na análise dos aspectos históricos, evidencia-se que a constituição das instituições marca sua organização administrativa, acadêmica e curricular. Diferentes estudos dedicados à análise da criação dos cursos superiores no Estado de São Paulo, por exemplo, descreveram os embates travados 
entre concepções de universidade e seu papel na formação da elite cultural e, por meio deles, pode-se compreender alguns aspectos que foram se sedimentando no atendimento da demanda pela formação de professores.

Com a aspiração de reunir "todos os ramos de investigação científica, de altos estudos, de cultura livre e desinteressada (para usar os termos do decreto de fundação) regendo-se pelo princípio da unidade do conhecimento e da formação intelectual" (Fétizon, 1994, p. 366), foi criada a primeira universidade no Estado de São Paulo e nela a estruturação das licenciaturas foi objeto de embate (Fétizon, 1994; Evangelista, 2002; Bontempi Jr., 2006 e Penin, 2012). Nos anos de 1950 a expansão dos cursos superiores teve lugar com a criação dos Institutos Isolados de Ensino Superior em diferentes cidades do interior do Estado, premidos entre o atendimento da necessidade crescente de formação de professores e a manutenção da seletividade no acesso aos cursos superiores (Vaidergorn, 2003; Castro, 2006). Essa política governamental configurou dois modelos de funcionamento dos cursos superiores e, consequentemente, de formação de professores: a centralização da formação numa grande universidade composta por diferentes faculdades e institutos ou faculdades de menor dimensão que centralizavam todas as ofertas formativas.

Nesse sentido, Fétizon (2012) destaca a fundação da USP, nos anos de 1930, no bojo de um projeto político cujo apelo se sustentava na relação direta com os problemas do sistema educacional. Entretanto, chama a atenção para o papel atribuído à formação dos professores na mesma universidade:

Acolhe, a Universidade, o Instituto de Educação somente por sua "escola de professores" - o curso em que recebiam formação pedagógica os professores secundários; e alija de seu instituto maior, aquele "propriamente universitário" (no dizer dos fundadores) - a Faculdade de Filosofia, Ciências e Letras - os estudos de educação (p. 200. Grifos da autora).

Na criação das faculdades isoladas, nos anos de 1950, a formação de professores também esteve no centro das críticas às políticas de expansão de oportunidades educacionais no interior do Estado. Saudadas pelas lideranças locais, tornaram-se objeto de intenso debate na imprensa, veiculado principalmente pelo jornal O Estado de S. Paulo. Foram retomados os argumentos que justificaram a criação da USP - a formação da elite dirigente do País - a fim de questionar a possibilidade de as faculdades recém-criadas garantirem as condições necessárias para formar cientistas e professores secundários. Nas palavras de Bontempi Jr., o jornal O Estado de S. Paulo criticava a "proliferação" das faculdades de filosofia porque essa política vinha trazendo "O abastardamento do título de licenciado", em outras palavras, conspurcando a legitimidade dos diplomas conferidos pela USP (Bontempi Jr., 2006, p. 147).

A recorrência desse problema de complexa solução é reposta por Ludke (2013), ao afirmar que, na passagem dos Institutos de Educação para o nível superior do sistema educativo, perde-se especialmente na articulação teoria e prática na formação dos professores. Essa articulação, 
como indicado anteriormente, representa problema de origem distante, consistindo no aspecto central para a compreensão da discussão empreendida neste texto:

\begin{abstract}
Foram tentadas várias soluções para procurar atender às duas exigências básicas, de formação teórica consistente e de iniciação à prática docente, como foi a criação dos Institutos de Educação, na década de 1930, [...] Esses Institutos passaram ao final da década para o nível superior e deram origem, na universidade, aos cursos de licenciatura, [...]. Esses cursos, entretanto, deixaram para trás a preocupação básica com a articulação entre a preparação teórica e a iniciação à prática, tão cara a Anísio Teixeira, e fizeram sua história muito mais centrada na valorização das disciplinas de conteúdo específico (Ludke, 2013, p. 115-116).
\end{abstract}

Demarcados elementos históricos e teóricos, que não podem ser ignorados na análise das organizações curriculares, é preciso também atentar para os aspectos legais nelas contidos que se avolumaram desde os anos de 1990. As reformas que envolvem a educação básica foram acompanhadas por mudanças relacionadas à elevação dos patamares de formação de seus docentes. Pela atual LDB, todos os professores da educação básica devem receber preparo profissional em nível superior, o que muda de maneira significativa o formato dos cursos de formação docente até então existentes e leva à expansão da abertura de cursos.

\section{Sobre os projetos pedagógicos}

\section{Universidade A}

Assumindo a complexidade e a premência que o problema educacional adquiriu nas últimas décadas, as duas universidades aqui abordadas criaram espaços institucionais de discussão específica sobre os cursos de licenciatura. A universidade A formou uma Comissão Permanente de Licenciatura - com representantes de todos os cursos de licenciatura -, entendida como "uma oportunidade ímpar de se pensar conjuntamente novos rumos para a formação de professores do ensino básico e para a integração da universidade com as escolas públicas" (Programa de Formação de Professores da universidade A, $2004^{2}$, p. 4).

Ao apresentar os objetivos do Programa, o documento resultante das discussões avalia que:

a maior parte dos Cursos de Licenciatura atualmente ministrados [...] tem ainda um caráter de complementação à formação profissional nas mais diversas áreas e que [...] a formação de professores é compreendida como uma superposição de dois conjuntos de conhecimentos, em que o aprendizado do saber disciplinar antecede o aprendizado do saber pedagógico (A.1, p. 1)

Desse modo, nos anos iniciais do século 21, confirmava-se no referido documento a permanência da desarticulação entre a parte específica e a
${ }^{2}$ Documento doravante denominado A.1. 
parte pedagógica do currículo das licenciaturas, apontada na produção acadêmica da área da educação.

Cabe entender esse programa de formação de professores como a expressão de um "compromisso de elaborar uma proposta efetiva para a formação [do professor da escola básica], de maneira a atender a legislação e as novas exigências colocadas pela sociedade e, principalmente, para marcar posição num projeto de sociedade mais justa e democrática" (A.1, p. 2). Nesse sentido, o primeiro princípio indicado no documento deixa clara a intenção de enfrentar a fragmentação da formação dos futuros professores nos cursos de licenciatura por meio do "empenho permanente de suas diversas unidades, de maneira a inspirar projetos integrados que visem preparar docentes para a educação básica, em seus níveis fundamental e médio" (A.1, p. 3). Afirma-se também a necessidade de integrar os trabalhos dos institutos e faculdades em torno da formação na licenciatura: "os conteúdos ligados à formação específica e os ligados à formação profissional do professor devem enriquecer-se mutuamente" (A.1, p. 5).

O projeto pedagógico do curso de Letras, apresentado em $2011^{3}$, concebido após a divulgação do programa de formação já referido, demonstra as dificuldades para a realização dos objetivos pretendidos.

Ainda que constem da divulgação dos cursos de Letras as modalidades bacharelado e licenciatura, ao indicar os objetivos o documento menciona apenas os que se referem ao bacharelado. Da mesma forma, no delineamento do perfil do profissional de Letras, encontram-se apenas duas indicações que dizem respeito às ações ligadas à atividade do ensino, de um total de dez indicações. Além disso, pode-se constatar que apenas uma delas se refere especificamente ao ensino na educação básica: (1) compreender como se processa a aquisição da linguagem e, por conseguinte, os problemas de ensino e aprendizagem da língua materna e de línguas estrangeiras; e (2) adotar métodos apropriados para o trabalho com textos literários no ensino fundamental e médio (A.2, p. 13). Na apresentação dos objetivos específicos das habilitações, nenhum se relaciona ao ensino (A.2, p. 14-15).

A estrutura do curso na universidade A permite que o estudante opte pelo bacharelado com licenciatura (que terá duração mínima de oito semestres). Nesse caso, a partir do quarto semestre, o estudante deve cursar disciplinas que o direcionem, mais especificamente, à licenciatura. Optando pelo bacharelado, não deverá cursar tais disciplinas. A esse respeito encontra-se a seguinte afirmação: "Se o aluno optar pela licenciatura, além do núcleo de disciplinas oferecidas pelos diversos departamentos que compõem o Curso de Letras [...], deverá cursar, na Faculdade de Educação, as disciplinas pedagógicas" (A.2, p. 17).

Quanto à estrutura, o curso consiste em "dois módulos [...]: a) um tem por objeto o estudo dos mecanismos da linguagem humana por meio do exame das diferentes línguas faladas pelo homem; b) o outro tem por finalidade a compreensão de um fato linguístico singular, que é a literatura" (A.2, p. 9).
${ }^{3}$ Documento doravante denominado A.2. 
Ao tratar da questão do papel da pesquisa na formação no curso de Letras, o documento ressalta que:

não se podem considerar apenas as atividades de pesquisa como atividades de criação e de inovação e as de ensino como de reprodução. [...] A questão é, portanto, fazer do ensino o lugar da pesquisa, levando os alunos a tornarem-se sujeitos do conhecimento, a buscarem informações, iniciando-os aos clássicos, aos problemas e às inovações da área; introduzindo-os ao estilo e às técnicas de trabalho próprias da área (A.2, p. 10-11).

O Item V do texto, Curso de Letras e Realidade Educacional Brasileira, trata das lacunas dos estudantes que chegam ao ensino superior e da maneira de se lidar com essa realidade (A.2, p. 15). Entretanto, não se encontra referência a ações ou preocupações com a formação de professores para o ensino básico, identificado como frágil ou insuficiente. Ao destacar as atividades de extensão oferecidas pela faculdade, há menção à ênfase nas atividades voltadas para os professores da rede pública de ensino básico, na oferta de cursos de formação continuada (A.2, p. 30).

No detalhamento das disciplinas do ciclo básico - cursado no primeiro ano do curso - e nas diferentes habilitações, não se encontra referência às disciplinas ligadas à licenciatura oferecidas pela Faculdade de Letras.

Cumpre destacar que o referido projeto assume um tom de descaso em relação ao seu papel na formação de professores para o ensino básico. Ainda que se identifique e que se ressalte a fragilidade da formação oferecida nesse nível de ensino, todos os destaques das atividades empreendidas no curso e na futura colocação profissional salientam a formação do bacharel em Letras. Mesmo com a indicação do interesse em oferecer atividades de extensão, de formação continuada, para os professores da rede pública de ensino, os aspectos ligados à sua formação inicial são deixados de lado, possivelmente como uma consequência da forma de divisão do trabalho de formação dos futuros professores na atuação de dois institutos: a Faculdade de Letras e a Faculdade de Educação. Merece destaque também a ausência de qualquer indicação, no projeto, de ações ligadas ao Programa de Formação de Professores da universidade, anteriormente referido.

Diante dessa opção por relegar a formação de professores à parte do curso desenvolvida na Faculdade de Educação, é importante destacar alguns elementos do projeto político pedagógico dessa unidade especialmente dedicado às demais licenciaturas - ou seja, sem que se considere a licenciatura em Pedagogia ${ }^{4}$. Nesse documento encontra-se a indicação clara de sua vinculação ao Programa de Formação de Professores da universidade:

As diretrizes e orientações gerais aqui propostas foram elaboradas a partir dos sete princípios expressos no Programa de Formação de Professores [...]. Trata-se de um documento que apresenta as linhas gerais para a formação de professores e que requer dos institutos e faculdades envolvidos projetos específicos e complementares (A.3, p.1).

\footnotetext{
${ }^{4}$ Documento denominado A.3.
} 
O documento indica como fluxo adequado da estrutura curricular para as disciplinas ministradas exclusivamente ou preferencialmente pela Faculdade de Educação: A) uma disciplina do bloco de Introdução aos Estudos de Educação, a ser cursada até o quarto semestre letivo (pré-requisito para cursar as disciplinas das áreas de didática, psicologia e políticas públicas de educação; B) a partir do semestre subsequente ao previsto para a disciplina do bloco de Introdução aos Estudos de Educação são cursadas as disciplinas das áreas de didática, psicologia e políticas (prérequisito para cursar as disciplinas do bloco de Metodologias do Ensino) e C) as disciplinas de Metodologia I (pré-requisito para a Metodologia II) e Metodologia II.

\section{Universidade $B$}

A discussão sobre as possibilidades e os desafios para a formação de professores ocorreu na universidade B, gerando comissões, fóruns de debates e proposição de ações. Em 2002 foi criada a Comissão de Estudos de Formação de Professores que, reunindo participantes de diferentes áreas do conhecimento, analisou a documentação já produzida sobre o tema bem como o histórico dos cursos de licenciatura e a legislação vigente e apontou que "formar professores na universidade implica um projeto específico e partilhado por todos os docentes da Licenciatura (não apenas os pedagogos)" (Tanuri et al., 2003, p. 214). Além da concepção geral, foram apresentadas diretrizes para a organização dos cursos, entre as quais se afirma a necessidade de considerar a história de constituição da própria universidade; a manutenção da qualidade dos cursos oferecidos; o estabelecimento de parcerias institucionais entre a universidade e a escola pública; a reconfiguração dos estágios e da prática de ensino para integração entre teoria e prática; mudanças organizacionais e administrativas e a construção de cursos com identidade própria ancorados na autonomia universitária.

O trabalho dessa Comissão lançou as bases para a criação de espaços institucionais para a discussão dessa modalidade de cursos de graduação, como a realização regular dos Fóruns das Licenciaturas, nos quais temas gerais e específicos têm sido objeto de análise e proposição de ações a serem consideradas na reformulação ou na criação dos cursos de formação de professores.

O projeto pedagógico do curso de Letras da Universidade B, elaborado no ano de $2007^{5}$, afirma conjugar uma formação geral - base para a formação de "um sujeito crítico e capaz de empreender a reflexão autônoma sobre a linguagem humana e suas manifestações literárias" e estudos sobre "culturas específicas, antigas e contemporâneas" (B.1, p. 2), de modo a formar licenciados e bacharéis em língua portuguesa e em língua estrangeira (a ser escolhida entre alemão, espanhol, francês, grego, inglês, italiano ou latim), habilitados para a docência no ensino

5 Documento doravante fundamental e médio e em outros campos de atuação profissional, bem como para o prosseguimento dos estudos. 
A área de conhecimento específico, como não poderia deixar de ser, centraliza os objetivos pretendidos e visa proporcionar aos alunos:

reflexão sobre questões em que estejam implicados o homem e sua natureza, em suas relações inter e extra pessoais, desde que pensados por meio de um objeto específico: a linguagem humana, em seus múltiplos aspectos e desdobramentos, quais sejam, literários, comunicativos, imbricados com artes plásticas ou outras formas de expressão artística (B.1, p. 1).

Explicita-se ainda que a formação oferecida é "essencialmente, pedagógica, isto é, visa à preparação do aluno para, um dia, comunicar o que aprendeu a outrem" e, por isso, o investimento nos:

conhecimentos necessários, como também [nas] posturas, comportamentos, motivações e reações características de um profissional destinado a não guardar apenas para si o patrimônio adquirido. A transferência desses conteúdos para outras pessoas é colocada não apenas como um compromisso técnico, mas como uma atitude relacional em que o sujeito enunciador e o destinatário receptor ligam-se não apenas pelo que deva ser veiculado, mas também pelo modo como esta operação será realizada (B.1, p. 3).

Para a consecução desses objetivos,

o aluno há de ser conduzido por um tríplice caminho: 1) o do domínio e da operacionalização das teorias linguísticas e literárias; 2) o da apropriação pessoal e autônoma das teorias estudadas, de modo a ser capaz de empreender a crítica devida, seja aos fundamentos metodológicos dessas teorias e suas consequências, seja à linguagem veiculada para propósitos determinados (por exemplo, a submissão de indivíduos ou de um grupo social a outro, operada por meio de discursos); 3) o do desenvolvimento de um discurso pessoal, de caráter dissertativo que, sem estar alicerçado em jargões acadêmicos - jargões e palavras de ordem não são, afinal, capazes de reformular saberes reflita sobre as determinações sociais da linguagem e represente um posicionamento próprio de quem é antes produtor crítico que mero reprodutor de discursos" (B.1, p. 4 e 5).

Quanto à estrutura do curso, o documento ressalta que para as modalidades de licenciatura e bacharelado deverá ser cursado um conjunto de disciplinas comuns e que a diferenciação ocorrerá com atividades e disciplinas de natureza pedagógica ou científica, segundo a opção realizada.

Os conteúdos selecionados para composição do currículo do curso de Letras atendem à legislação vigente e abrangem:

a) domínio teórico e descritivo dos componentes fonológico, morfossintático, léxico e semântico de uma língua; b) domínio de diferentes noções de gramática e (re)conhecimento das variedades linguísticas existentes, bem como dos vários níveis e registros da linguagem; c) capacidade de analisar, descrever e explicar, diacrônica e sincronicamente, a estrutura e o funcionamento da língua; d) capacidade de compreender os fatos da língua e de conduzir investigações de língua e linguagem, por meio da análise de diferentes teorias e de sua aplicação 
a problemas de ensino e aprendizagem da língua materna e de línguas estrangeiras; e) domínio ativo e crítico de um repertório representativo de uma dada literatura; f) domínio de conhecimento histórico e teórico necessário para refletir sobre as condições nas quais a escrita se torna literatura; g) domínio de repertório de termos especializados por meio dos quais se pode discutir e transmitir a fundamentação do conhecimento da língua e da literatura" (B.1, p. 7).

A certificação para a licenciatura exige 90 horas de estágio vinculado a diferentes disciplinas - Organização e Desenvolvimento da Educação Básica, Psicologia da Educação, Didática e Trabalho Docente -, além da Prática de Ensino propriamente dita, que articula as atividades relacionadas ao trabalho docente. Há ainda, na estrutura curricular, disciplinas que objetivam materializar a interface entre os dois âmbitos necessários à formação, tais como: Leitura e Produção de Textos; Aquisição da Linguagem e Aquisição da Língua Escrita e Literatura na Sala de Aula.

\section{Conclusões}

Neste texto foram analisados os currículos de dois cursos de formação de professores de língua portuguesa para a educação básica, oferecidos por duas universidades públicas do Estado de São Paulo. A formação de professor para lecionar na educação básica é regida por legislação nacional, complementada em nível estadual, e pode ser oferecida por universidades e outras instituições de nível superior. As universidades, no âmbito da autonomia de que gozam por lei, estruturam e organizam seus próprios cursos tendo em vista as orientações gerais e básicas da formação de professores, mas também respondem ao que é peculiar à missão da instituição, assim como aos fins definidos em sua própria fundação. As duas universidades aqui tratadas são relativamente recentes, ainda que uma delas (A) faça parte da origem das instituições de ensino superior, modalidade universidade, no País, no início dos anos 30 do século 20. Da missão de uma universidade faz parte o impulso para a inovação, ousando propor e experimentar, com a desejável avaliação sistemática, melhores resultados de suas atribuições vis-à-vis uma análise cuidadosa das necessidades da nação para o seu desenvolvimento e a melhoria da qualidade de vida da população. Paradoxalmente, a universidade, desde as primeiras no século 12, busca mirar o futuro, propondo-se a "cultivar a mais lúcida consciência de uma determinada época" (Jaspers, apud Santos, 1996), mas também se curva ao seu próprio passado, de modo que nesse embate dialético vai construindo sua própria história. Das tarefas básicas propostas por uma universidade na atualidade - ensino, pesquisa e cultura-extensão - as duas universidades em questão têm sido bem avaliadas em nível nacional e mesmo internacional, tendo na pesquisa um ponto de destaque. Diferente da pesquisa e da produção humanísticocientífica, a formação de profissionais é principalmente avaliada em nível nacional, com critérios rigorosos ou não, por toda a população. 
Quanto à formação de professores para a educação básica, é possível afirmar a presença significativa de parte do corpo docente dessas duas universidades no debate nacional, que vem suscitando a proposição de leis ou normas. Em geral, propostas hegemônicas nesse debate nunca são unânimes, e em cada instituição as divergências continuam a ocorrer.

Nesse processo o mais ponderado, haja vista a natureza da instituição, é definir um caminho com critérios rigorosos, legitimados pela comunidade. Mas, sobretudo, de uma universidade, espera-se que o espírito investigativo permaneça em todas as suas manifestações e que as definições curriculares entre tantas outras sejam acompanhadas e avaliadas rigorosamente. Nesse sentido, pesquisa como a que encerra este texto tem também o objetivo de oferecer elementos para avaliações desenvolvidas por toda a universidade: avaliação institucional, de unidade, de departamento e, em especial, de curso e de currículo. Na base desse objetivo está a crença no valor qualitativo da avaliação e no movimento dialético do real.

Quanto à análise realizada sobre os currículos de formação de professores de língua portuguesa, observou-se que na universidade A parece existir um peso significativo do lugar, significado e sentido que a incorporação da formação de professores que ocorria em outra instituição provocou no momento de sua criação e em momentos sucessivos até a atualidade. É possível afirmar que a busca da quebra do modelo 3+1 na formação dos docentes para a educação básica, se abrandada, não logrou o conjunto dos objetivos delineados na formação específica de professores para o ensino da língua portuguesa na educação básica. Isso parece ter ocorrido mesmo com o fervor das intensas e prolongadas discussões que antecederam a definição do Programa de Formação de Professores em 2004, reformulando a estrutura e a organização dos cursos e articulando de diferentes modos as unidades envolvidas numa específica área de formação. Essa suposição não pode ser generalizada para as outras áreas de formação de professores para a educação básica, que percorreram caminhos diferentes; são necessárias pesquisas específicas para cada caso, pois a complexidade da questão e a diversidade de cada unidade de ensino é algo que certamente interfere no processo.

Como se pode depreender da análise documental aqui apresentada, a necessária integração entre saberes pedagógicos e saberes provenientes da área de referência não é tarefa fácil a ser cumprida em curto prazo. A formação superposta sedimentou-se nas instituições e as tentativas para superá-la constituem exemplos esparsos e não modelos generalizados.

Os problemas dirigidos à formação de professores permanecem distantes de solução, ainda que temporárias. Oportunidades para discussões e para a construção de novos arranjos curriculares abrem-se mediante indicações legais. A atribuição formal de carga horária pela legislação - bem como outras formas de prescrição - tem sido um importante instrumento na organização dos cursos de formação de professores, mas sua efetivação parece depender em igual medida das relações institucionais e organizacionais. 
Embora não se possa afirmar que o currículo prescrito espelhe todo o esforço empreendido para constituir a formação de professores como área de conhecimento específica, nota-se que ele efetivamente expressa tensões provenientes tanto das concepções mais amplas quanto dos entraves institucionais, mais ou menos determinantes segundo as características organizacionais historicamente produzidas.

\section{Referências bibliográficas}

BONTEMPI JR., Bruno. Em defesa de legítimos interesses: o ensino secundário no discurso educacional de O Estado de S. Paulo 19461957. Revista Brasileira de História da Educação, Campinas, n. 12, p. 121-158, jul./dez. 2006.

CARVALHO, José S. O discurso pedagógico das diretrizes curriculares: competência crítica e interdisciplinaridade. Cadernos de Pesquisa, n. 112, p. 155-165, 2001. Disponível em: < http://www.scielo.br/pdf/cp/ n112/16106.pdf>.

CASTRO, Rosane M. de. A produção acadêmica sobre os Institutos Isolados de Ensino Superior do Estado de São Paulo (1951-1964). Revista Brasileira de História da Educação. Campinas, n. 12, p. 159191, jul./dez. 2006.

EVANGELISTA, Olinda. A formação universitária do professor: Instituto de Educação da Universidade de São Paulo (1934-1938). Florianópolis: NUP: Cidade Futura, 2002.

FÉTIZON, Beatriz A. de Moura. Faculdade de Educação: antecedentes e origens. Estudos Avançados, São Paulo, v. 8, n. 22, p. 365-374, set./dez. 1994.

FÉTIZON, Beatriz A. de Moura. A Universidade e sua alma endemoninhada. São Paulo: FEUSP, 2012. 247 p. (Série Estudos \& Documentos, v. 45). Disponível em: < http://www4.fe.usp.br/wpcontent/uploads/estudos-documentos-451.pdf $>$.

FREITAS, Helena C. L. Certificação docente e formação do educador: regulação e desprofissionalização. Educação \& Sociedade, Campinas, v. 24, n. 85, p. 1095-1124, dez. 2003.

GIMENO SACRISTÁN, Jose. O que são os conteúdos do ensino?. In: GIMENO SACRISTÁN, J; PÉREZ GÓMEZ, I. Compreender e transformar o ensino. Porto Alegre: Artmed, 1998, p. 149-195.

GIMENO SACRISTÁN, José; PÉREZ GÓMEZ, I. Compreender e transformar o ensino. Porto Alegre: Artmed, 1998. 
GOODSON, Ivor F. A construção social do currículo. Lisboa: Educa, 1997.

KUENZER, Acácia Z. N. As Políticas de formação: a constituição de identidade do professor sobrante. Educação \& Sociedade, Campinas, v. 20, n. 68, p. 63-188, dez. 1999.

LUDKE, Menga. Avaliação institucional: formação de docentes para o ensino fundamental e médio (as licenciaturas). Cadernos CRUB, Brasília, DF, p. 5-95, 1994.

LUDKE, Menga. O lugar do estágio na formação de professores.

Educação em Perspectiva, Minas Gerais, v. 4, n. 1, p. 111-131, 2013.

LUDKE, Menga; CRUZ, G. B. Aproximando universidade e escola de educação básica pela pesquisa. Cadernos de Pesquisa, São Paulo, v. 35, n. 125, p. 81-109, 2005.

LUDKE, Menga; MOREIRA, Antônio F. B.; CUNHA, Maria I.

Repercussões de tendências internacionais sobre a formação de nossos professores. Educação \& Sociedade, Campinas, v. 20, n. 68, p. 278-298, 1999.

MARQUES, C. A.; PEREIRA, J. E. D. Fóruns das licenciaturas em universidades brasileiras: construindo alternativas para a formação inicial de professores. Educação \& Sociedade, Campinas, v.23, n. 78, p.171-183, abr. 2002.

MAUÉS, O. C. Reformas internacionais da educação e formação de professores. Cadernos de Pesquisa, São Paulo, n.118, p. 89-117, 2003.

OLIVEIRA, M. B. F. Revisitando a formação de professores de língua materna: teoria, prática e construção de identidades. Revista Linguagem em (dis)curso, v. 6, n. 1, p. 101-117, 2006.

PENIN, Sonia T. de S. Pedagogia: área de conhecimento e cursos articulados. In: ENCONTRO NACIONAL DE DIDÁTICA E PRÁTICAS DE ENSINO - ENDIPE, 16., 2012. Campinas. Disponível em: < http://www. infoteca.inf.br/endipe/smarty/templates/arquivos_template/upload_ arquivos/acervo/docs/0062s.pdf>.

PEREIRA, J. E. D. As licenciaturas e as novas políticas educacionais para a formação docente. Educação \& Sociedade, Campinas, v. 20, n. 68, p. 109-125, 1999.

PONTE, João P. A Investigação sobre o professor de matemática: problemas e perspectivas. 2000. Disponível em: <http://www.educ. fc.ul.pt/docentes/jponte/curso_rio_claro.htm $>$. 
REGO, Teresa C.; MELLO, Guiomar N. La Formación docente en América Latina y el Caribe: en busca de la innovación y efectividad. In: MAESTROS en América Latina: nuevas perspectivas sobre su formación y desempeño. Santiago de Chile: San Marino/PREAL, p. 165-212, 2004.

SANTOS, Boaventura S. Pela mão de Alice: o social e o político na pósmodernidade. 2 ed. São Paulo: Cortez, 1996.

SCHEIBE, Leda; BAZZO, Vera L. Diretrizes Curriculares Nacionais para os cursos de Licenciatura no Brasil: da regulamentação aos projetos institucionais. Educação em Perspectiva, v. 4, n. 1, p. 15-36, jan./jul. 2013.

SHULMAN, R. J. Those who understand: knowledge growth in teaching. Educational Researcher, v. 15, n. 2, p. 4-14, 1986.

SILVA, S. R. P. da. A Avaliação da aprendizagem no contexto da organização do ensino por ciclos com progressão continuada: um estudo a respeito de representações de professoras do ciclo I de uma escola municipal. 2005. Tese (Doutorado em Educação) - Universidade de São Paulo, São Paulo, 2005.

TANURI, L. M. et al. Pensando a licenciatura na UNESP. Nuances, v. 9, n. 9-10, p. 211-229, jan./dez. 2003.

VAIDERGORN, Jose. As seis irmãs: as FFCL do interior paulista. Araraquara: Laboratório Editorial; São Paulo: Cultura Acadêmica, 2003.

Sonia T. S. Penin, doutora em Educação pela Universidade de São Paulo (USP), é professora titular do Departamento de Metodologia do Ensino e Educação Comparada da Faculdade de Educação da USP, São Paulo, Brasil.

spenin@uol.com.br

Cláudia V. A. Galian, doutora em Educação pela Pontifícia Universidade Católica de São Paulo (PUC-SP), é docente do Departamento de Metodologia do Ensino e Educação Comparada da Faculdade de Educação da Universidade de São Paulo (USP), São Paulo, Brasil.

claudiavalentina@usp.br 
Vera Valdemarin, doutora em Educação pela Universidade de São Paulo (USP), é professora adjunta do Departamento de Ciências da Educação da Faculdade de Ciências e Letras de Araraquara, do Programa de Pós-Graduação em Educação do Instituto de Biociências de Rio Claro (docente permanente), ambos da Universidade Estadual Paulista Julio de Mesquita Filho (Unesp).

veravaldemarin@gmail.com.br

Recebido em 19 de dezembro de 2013.

Aprovado em 28 de janeiro de 2014. 